\title{
Parachromis managunesis (Günther, 1867): Keberadaan Ikan Predator Asing di Pulau Lombok, Nusa Tenggara Barat
}

\author{
Parachromis managunesis (Günther, 1867): Presence of Foreign Predatory Fish in Lombok, West \\ Nusa Tenggara \\ Veryl Hasan ${ }^{1)^{*}}$, Maheno Sri Widodo ${ }^{2)}$ \\ ${ }^{1}$ Program Studi Akuakultur, Fakultas Perikanan dan Kelautan, Universitas Airlangga, Surabaya, \\ Jawa Timur \\ ${ }^{2}$ Program Studi Budidaya Perairan, Fakultas Perikanan dan IImu Kelautan, Universitas Brawijaya, \\ Malang, Jawa Timur.
}

Penulis korespondensi : Email : veryl.hasan@fpk.unair.ac.id

(Diterima Agustus 2021/ Disetujui Oktober 2021)

\begin{abstract}
The entry of foreign predatory fish into Indonesian open waters had the potential as a disease vector, predation, and damaging food webs that would have a systemic impact on the local ecosystem. In this study, we report the presence of the foreign predatory fish Jaguar cichlid Parachromis managuensis (Günther, 1867) from Central America in the Lingsar River, West Lombok Regency. This record is the first time for this species in Lombok, where previously this fish was found in Java. A description of the morphological characters of the captured specimens is provided in the discussion.
\end{abstract}

Keywords: Biodiversity, ecology, ecosystem, foreign predatory fish, freshwaters.

\begin{abstract}
ABSTRAK
Masuknya ikan predator asing ke perairan terbuka Indonesia memliki potensi sebagai vector penyakit, predasi dan terganggunya rantai makanan yang berdampak sistemik pada ekosistem lokal. Dalam penelitian ini kami melaporkan keberadaan ikan predator asing Jaguar cichlid Parachromis managuensis (Günther, 1867) asal Amerika Tengah di Sungai Lingsar, Kabupaten Lombok Barat. Catatan ini meruapakan yang pertama kalinya untuk spesies ini terekam di Lombok, dimana lokasi sebelumnya ikan ini sudah pernah ditemukan di Jawa. Deskripsi mengenai karakter morfologi dari specimen yang tertabngkap disediakan dalam pembahasan.
\end{abstract}

Kata kunci: Biodiversitas, ekologi, ekosistem, ikan predator asing, perairan tawar.

\section{PENDAHULUAN}

Jagua Cichlid Parachromis managuensis (Günther, 1867) merupakan ikan air tawar yang berasal dari Nicarague, Costa Rica, dan Honduras (Bussing 1998). Ikan ini telah lama di inroduksi ke berbagai negara sebagai ikan hias antara lain Amerika Utara (Gestring dan Shafland 1997), Amerika Selatan (Magalhães dan Vitule, 2013), dan Asia Tenggara (Agasen et al. 2006; Hasan et al. 2020a). Ikan ini termasuk predator rakus yang memakan hewan lain berukuran lebih kecil seperti anak ikan, mollusca dan crustacea. Selain itu spesies ini juga sangat adaptif terhadap lingkungan baru sehingga bisa dengan mudah menjadi spesies invasive di periaran lokal (Yamamoto dan Annete 2000).

Jaguar cichlid banyak dijumpai di pedagang ikan hias sebagai hewan peliharaan dan tidak pernah tercatat sebagai komoditas budidaya di Indonesia. Di Asia Tenggara, ikan ini berkembang dengan pesar di Danau Taal Filipina dan beberapa perairan umum di Pulau Jawa, Indonesia (Agasen et al. 2006; Hedianto et al. 2013; Dahruddin et al. 2017; Hasan et al. 2020). Sungai Lingsar merupakan salah satu sungai utama di Kabupaten Lombok Barat, Nusa Tenggara Barat, dan tidak tercatat

To Cite This Paper: Hasam, V. dan Widodo, M.S. 2021. Parachromis managunesis (Günther, 1867): Keberadaan Ikan Predator Asing di Pulau Lombok, Nusa Tenggara Barat. Samakia: Jurnal IImu Perikanan, 12 (2) : 180-184

Journal Homepage: http://samakia.ibrahimy.ac.id/index.php/JSAP 
sebagai lokasi budidaya ikan hias eksostis. Keberadaan Jaguar cichlid di periaran tersebut merupakan catatan baru.

\section{MATERI DAN METODE}

\section{Waktu dan Tempat}

Individu Jaguar cichlid dengan panjang total $(T L) 16 \mathrm{~cm}$ (Gambar 2) secara tidak sengaja didapatkan oleh pemancing lokal pada 20 Mei 2020 mengunakan kail sedang di Sungai Lingsar, Kabupaten Lombok Barat (8³4'24"S; 116 08'38"E) (Gambar 2). Sungai Lingsar merupakan salah satu sungai utama di Lombok Barat yang digunakan oleh masyarakat sebagai sumber irigasi dan objek wisata rafting. Identifikasi spesies menggunakan pendekatan morfologi berdasarkan Kullander dan Hartel (1997).

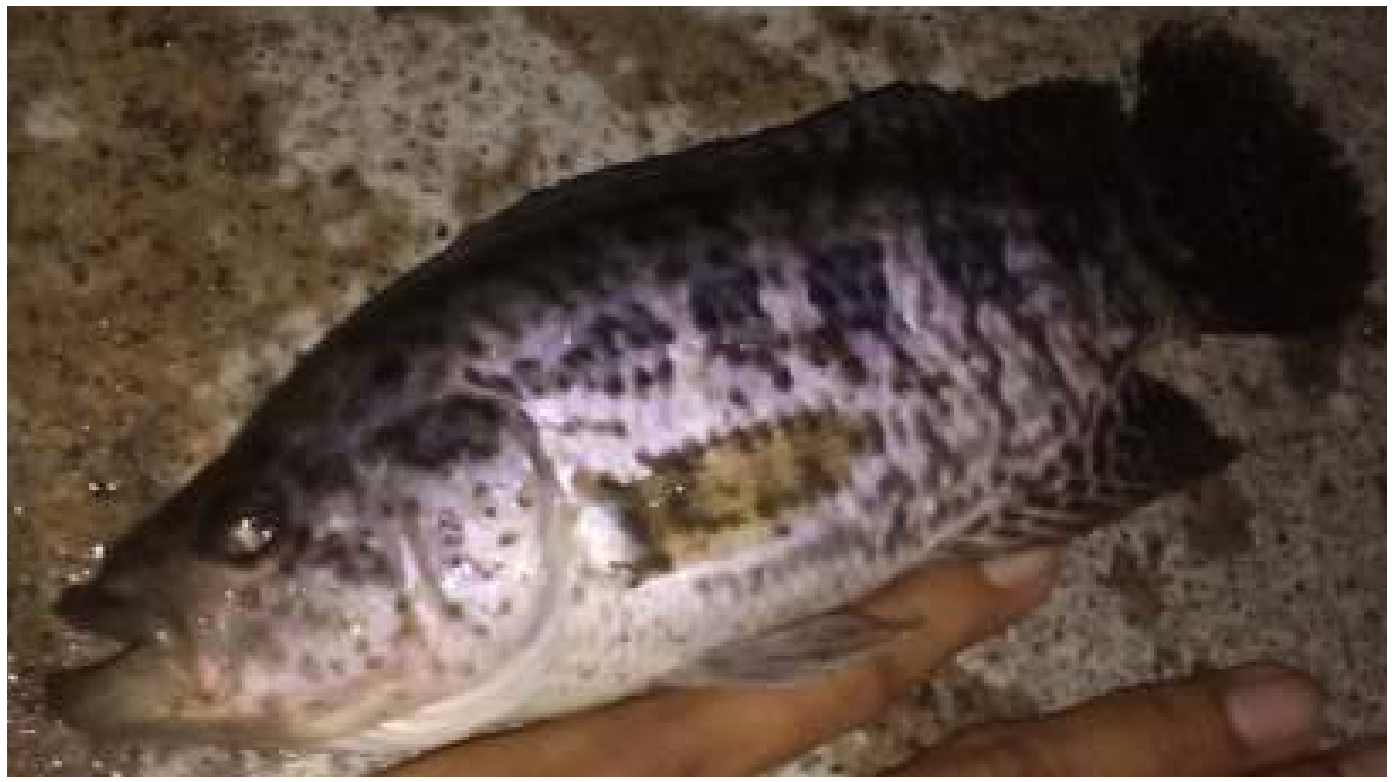

Gambar 2. Individu Jaguar cichlid (Foto: Madan Ssfc Lombok)

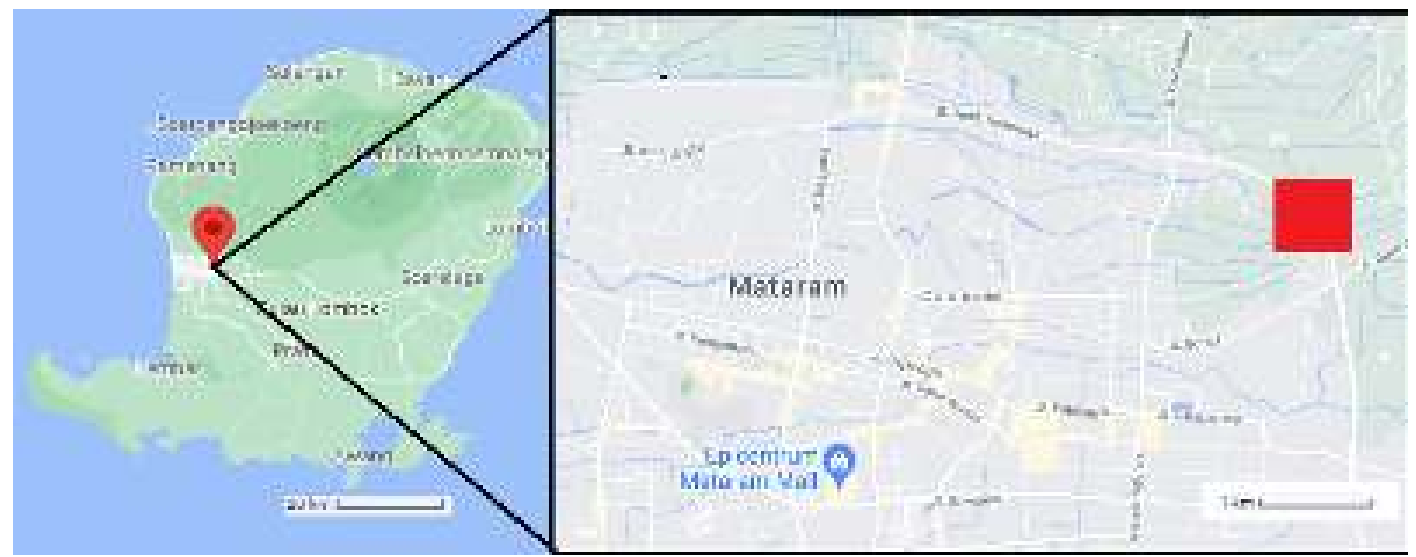

Gambar 2. Peta lokasi sampling

HASIL DAN PEMBAHASAN

Individu Jaguar cichlid yang tertangkap di Sungai Langsar, Kabupaten Lombok Barat memiliki ciriciri karakter morfologi sebagai berikut: Kepala besar dengan ujung moncong tumpul, mulut besar, dengan deratan gigi tajam pada rahang atas dan rahang bawahnya, mata sedang, bentuk tubuh pipih seperti family Cichlidae pada umumnya. Pola warna dasar tubuh ungu keperakan, terdapat

To Cite This Paper: Hasam, V. dan Widodo, M.S. 2021. Parachromis managunesis (Günther, 1867): Keberadaan Ikan Predator Asing di Pulau Lombok, Nusa Tenggara Barat. Samakia: Jurnal IImu Perikanan, 12 (2) : 180-184

Journal Homepage: http://samakia.ibrahimy.ac.id/index.php/JSAP 
motif warna lurik hitam dari ujung kepala sampai ekor, pada sirip punggung, sirip perut, sirip anal dan sirip ekor terdapat warna totol hitam, sedang sirip dada transparan. Karakter yang telah dijelaskan ini sesuai dengan ciri-ciri morfologi Jaguar cichlid menurut Kullander dan Hartel (1997). Sejauh ini kerabat terdekat Jaguar cichlid dalam satu genus Parachromis belum pernah masuk ke Indonesia, sehingga kerabat terdekat yang bisa dibandingkan adalah dengan sesame family cichlidae. Dibandingkan spesies lain dalam family cichlidae yang sudah masuk ke Indonesia, Jaguar cichlid memilikiu karakter mencolok berupa pola warna tubuh mirip jaguar yaitu dipenuhi bintikik hitam, sedangkan dibandingkan proporsi badannya Jaguar cichlid memiliki mulut dan rahang yang lebih besar daripada spesies lain dalam family cichlidae yang sudah masuk ke Indonesia.

Masuknya Jaguar cichlid mengkhawatirkan bagi ekosistem lokal karena memiliki karakteristik yang toleran terhadap perubahan lingkungan seperti fluktuasi suhu dan kandungan oksigen rendah. Selain itu ikan ini juga mampu berkembangbiak sepanjang tahun sehingga sangat memungkinkan terjadi Ionjakan populasi apabila masuk ke perairan terbuka. Kejadian ini dapat menyebabkan punahnya ikan-ikan lokal akibat predasi yang massif dari Jaguar cichlid, sedangkan keberadaan ikan lokal di Indonesia saat ini membutuhkan perhatian lebih untuk diselamatkan populasinya (Hasan et al. 2020b; Hasan et al. 2021a). Induk Jaguar cichlid sangat protektif terhadap telur dan larvanya sehingga potensi individu baru bertahan hidup sangat besar (Agasen et al. 2006).

Kami berspekulasi masuknya Jaguar cichlid ke perairan terbuka di Lombok Barat akibat perdagangan akuarium (Hasan et al. 2020c; Hasan et al. 2020d; Serdiati et al. 2021) atau bahkan budidaya namun tanpa perizinan yang jelas (Hasan dan Tamam 2019; Hasan et al. 2019a). Kasus masuknya ikan asing ke perairan terbuka di Indonesia telah banyak terjadi sebelumnya dan hampir terjadi di semua wilayah Kepulauan Indonesia (Insani et al. 2020; Wijayanti et al. 2021). Butuh perhatian lebih dari pemerintah agar membuat aturan tegas mengenai peredaran ikan asing predator serta komitmen dari masyarakat agar tidak melepas ikan asing ke perairan terbuka di Indonesia. Jika tidak, maka kerusakan ekosistem terutama punahnya ikan-ikan lokal akan terjadi dalam waktu dekat (Hasan et al. 2021b; Hasan et al. 2019b; Hasan et al. 2019c; Hasan et al. 2019d)

\section{KESIMPULAN}

Jaguar cichlid merupakan ikan predator asing berasal dari Amerika Tengah yang didatangkan ke Indonesia sebagai bagian dari komoditas ikan hias. Keberadaan ikan ini di Sungai Lingsar, Kabupaten Lombok Barat merupakan yang pertama kali tercatat dimana sebelumnya ikan ini sudah oernah tercatat di Jawa. Ikan ini berbahaya bagi ekosistem lokal sehingga keberadaannya di periaran terbuka seharusnya dihindari agar tidak terjadi kerusakan lingkungan.

\section{SARAN}

Perlu adanya penelitian lebih lanjut sampai dimana rentang ekspansi Jaguar cichlid di Pulau Lombok, sehingga dapat diambil tindakan pencegahan atau penanggulangan agar spesies ini tidak tersebar ke daerah lain.

\section{DAFTAR PUSTAKA}

Agasen, E.V. Clemente, J.P. Rosana, M.R. and Kawi, N.S. 2006. Biological Investigation of Jaguar Guapote Parachromis managuensis (Gunther) in Taal Lake, Philippines. J. Environ. Sci. Manag 9(2): 20-30.

Bussing, W.A. 1998. Peces de Las Aguas Continentales de Costa Rica (Freshwater Fishes of Costa Rica), 2nd editio. Editorial de la Universidad de Costa Rica, San José.

Dahruddin, H. Hutama, A. Busson, F. Sauri, S. Hanner, R. Keith, P. Hadiaty R. and Hubert, N. 2017. Revisiting the ichthyodiversity of Java and Bali through DNA barcodes: taxonomic

To Cite This Paper: Hasam, V. dan Widodo, M.S. 2021. Parachromis managunesis (Günther, 1867): Keberadaan Ikan Predator Asing di Pulau Lombok, Nusa Tenggara Barat. Samakia: Jurnal IImu Perikanan, 12 (2) : 180-184

Journal Homepage: http://samakia.ibrahimy.ac.id/index.php/JSAP 
coverage, identification accuracy, cryptic diversity and identification of exotic species. Mol. Ecol. Resour 17(2): 288-299.

Gestring, K.B. and Shafland, P.L. 1997. Status and selected life history attributes of the exotic Jaguar Guapote (Cichlasoma managuense) in Florida. Florida Sci 60(3): 137-142.

Hasan V, Pratama F, Malonga WAM, Cahyanurani AB. 2019d. First record of the Mozambique Tilapia Oreochromis mossamibicus Peters, 1852 (Perciformes: Cichlidae) on Kangean Island, Indonesia. Neotropical Biology and Conservation 14(2) : 207-211.

Hasan V, Soemarno, Widodo MS, Wiadnya DGR, Mukti AT, Irawan B. 2019b. Distribution extension and first record of Lobocheilos falcifer (Cypriniformes, Cyprinidae) in Central Java Province, Indonesia. Ecology, Environment and Conservation 25(July Suppl. Issue): S158S161.

Hasan V, Soemarno, Widodo MS, Wiadnya DGR. 2019c. Lobocheilos falcifer (Valenciennes, 1842) (Cyrpiniformes, Cyprinidae): distribution extension in Java and first record from Tuntang river, Semarang Regency, Indonesia. Ecology, Environment and Conservation 25(4): 17131715.

Hasan V, Soemarno, Widodo MS, Wiadnya DGR. 2020b. New distributional record of the Beardless barb Cyclocheilichthys apogon (valenciennes, 1842) (Cypriniformes: Cyprinidae) from madura island, Indonesia. BIOTROPIA, in press

Hasan, V. 2021b. Range expansion of the Invasive Nile Tilapia Oreochromis niloticus (Perciformes: Cichlidae) in Sulawesi Sea and first record for Sangihe Island, Tahuna, North Sulawesi, Indonesia. Eco. Env. \& Cons. 27(1): 168-171.

Hasan, V. and Tamam, M.B. 2019. First record of the invasive Nile Tilapia, Oreochromis niloticus (Linnaeus, 1758) (Perciformes, Cichlidae), on Bawean Island,Indonesia. Check List 15(1): 225227.

Hasan, V., Faqih, A.R., Maftuch. 2020a. Range expansion of Parachromis managuensis (Günther, 1867) (Perciformes, Cichlidae) in Java, Indonesia. BIOTROPIA, in press.

Hasan, V., Mukti, A.T. and Putranto, T.W.C. 2019. Range Expansion of the Invasive Nile Tilapia Oreochromis Niloticus (Perciformes: Cichlidae ) in Java Sea and First Record for Kangean Island, Madura, East Java, Indonesia. Eco.Env. \& Cons. 25: S187-S189.

Hasan, V., Valen, F.S., Islamy, R.A., Widodo, M.S., Saptadjaja, A.M., Islam, I. 2021. Short Communication: Presence of the vulnerable freshwater goby Sicyopus auxilimentus (Gobiidae, Sicydiinae) on Sangihe Island, Indonesia. Biodiversitas, 22: 573-581.

Hasan, V., Widodo, M.S., Faqih, A.R., Mahasri, G., Arief, M., Valen, F.S, Tamam, M.B, Yonarta, D., Pratama, F.S, Fitriadi, R. 2020d. Presence of striped flying barb Esomus metallicus (Teleostei, Cyprinidae) from west Sumatra, Indonesia. Ecology, Environment and Conservation 26(August Suppl. Issue): S73-S75.

Hasan, V., Widodo, M.S., Islamy, R.A., Pebriani, D.A.A. 2020c. New records of alligator gar, Atractosteus spatula (Actinopterygii: Lepisosteiformes: Lepisosteidae) from Bali and Java, Indonesia. Acta Ichthyologica et Piscatoria 50(2): 233-236.

Hasan, V., Wijayanti, A., Tamam, M.B., Islamy, R.A., Widodo, M.S. 2021a. Beardless barb Cyclocheilichthys apogon (Valenciennes, 1842) (Cypriniformes, Cyprinidae): Distribution extension and first record from South Bali. IOP Conf. Series: Earth and Environmental Science 679 (2021) 012077.

Hedianto, D.A., Purnomo, K. And Warsa, A. 2013. Interactions of food resources ulitization by fish communities in penjalin reservoir, Central Java. Bawal 5(1): 33-40.

To Cite This Paper: Hasam, V. dan Widodo, M.S. 2021. Parachromis managunesis (Günther, 1867): Keberadaan Ikan Predator Asing di Pulau Lombok, Nusa Tenggara Barat. Samakia: Jurnal IImu Perikanan, 12 (2) : 180-184

Journal Homepage: http://samakia.ibrahimy.ac.id/index.php/JSAP 
Insani, L., Hasan, V., Valen, F.S., Pratama, F.S, Widodo, M.S, Faqih, A.R, Islamy, R.A, Mukti, A.T, Isroni, W. 2020. Presence of the invasive nile tilapia Oreochromis niloticus Linnaeus, 1758 (perciformes, cichlidae) in the Yamdena Island, Indonesia. Ecology, Environment and Conservation 26(3): 1115-1118.

Kullander, S.O. dan Hartel, K.E. 1997. The systematic status of cichlid genera described by Louis Agassiz in 1859: Amphilophus, Baiodon, Hypsophrys and Parachromis (Teleostei: Cichlidae). Ichthyol. Explor. Freshwaters 7: 193-202.

Magalhães, A.L.B. dan Vitule, J.R.S. 2013. Aquarium industry threatens biodiversity. Science 341 (6145): 457.

Serdiati N., Insani L., Safir M., Rukka AH., Mangitung SF., Valen FS, Tamam MB. and Hasan V. 2021. Range expansion of the Invasive Nile Tilapia Oreochromis niloticus (Perciformes: Cichlidae) in Sulawesi Sea and first record for Sangihe Island, Tahuna, North Sulawesi, Indonesia. Ecology, Environment and Conservation 27(1): 173-176.

Wijayanti, A., Hasan, V. and Tamam, M.B. 2021. Range expansion of Oreochromis niloticus (Linnaeys, 1758) (Perciformes, Chichlidae) in Java Sea and first record for Masalembo Island. IOP Conference Series Earth and Environmental Science 718(1): 012096

Yamamoto, M.N. and Annete, W.T. 2000. Hawai'i's Native and Exotic Freshwater Animals. Mutual Publishing, Honolulu 